\title{
O SER-NO-MUNDO NA INFÂNCIA
}

Juliana Tibério ${ }^{1}$

RESUMO: O presente trabalho pretende abordar o tema da infância no pensamento do filósofo alemão Martin Heidegger (1889-1976). A investigação desse tema é conduzida a partir do seguinte problema: a criança também é um Dasein? Diante desta questão, o objetivo geral é compreender a noção de ser-no-mundo e a partir daí fazer uma análise sobre o ser-no-mundo na infância. No entanto, para tal compreensão foi necessário fazer uma introdução ao pensamento do filósofo. Dessa forma, buscou-se validar a hipótese de que para Heidegger o que está em jogo quando se trata do ser criança é o ser-aí humano, a sua abertura para o mundo. Assim, constata-se que os significados das coisas aparecem para a criança da mesma maneira que para um adulto, no entanto, isso não quer dizer que os significados das coisas terão o mesmo sentido para ambos, pois, apenas o processo é igual. $\mathrm{O}$ artigo se justifica, prioritariamente, pela ausência de um debate maior sobre os vários modos de ser criança. A pesquisa é totalmente de cunho bibliográfico.

Palavras-chave: Ser-aí; Ser-no-mundo; Infância.

\section{THE BEING-IN-THE-WORLD IN CHILDHOOD}

\begin{abstract}
The present work intends to approach the theme of childhood in the thought of the German philosopher Martin Heidegger (1889-1976). The investigation of this theme is based on the following problem: is the child also a Dasein? Faced with this question, the general objective is to understand the notion of being-in-the-world and, from there, make an analysis of being-in-the-world in childhood. However, for such an understanding it was necessary to make an introduction to the philosopher's thought. Thus, we sought to validate the hypothesis that for Heidegger what is at stake when it comes to being a child is the human being, his opening to the world. Thus, it appears that the meanings of things appear to the child in the same way as to an adult, however, this does not mean that the meanings of things will have the same meaning for both, as only the process is the same. The article is justified, primarily, by the absence of a greater debate on the various ways of being a child. The research is entirely bibliographic in nature.
\end{abstract}

Keywords: Be-there; Being-in-the-world; Childhood,

\section{INTRODUÇÃO}

O presente trabalho pretende abordar o tema da infância no pensamento do filósofo alemão Martin Heidegger (1889-1976). Inicialmente foi feita uma introdução ao

\footnotetext{
${ }^{1}$ Graduada em Filosofia pela Universidade Estadual do Oeste do Paraná (UNIOESTE), pedagogia pela Uninter, mestranda em Filosofia na Unioeste. E-mail: juh_ana_gt@hotmail.com 
pensamento do filósofo, abordando como se iniciou sua carreira na filosofia e explicando seus principais conceitos. Em seguida foi exposto como o filósofo compreende a noção de ser-no-mundo de uma forma geral, a partir daí, foi feita uma análise do ser-no-mundo na infância.

Martin Heidegger nasceu na cidade de Messekisch no sudoeste da Alemanha, formou-se em teologia e filosofia na Universidade de Freiburg e tornou-se um dos principais filósofos do seu século ao reformular a fenomenologia de Edmund Husserl. O objetivo de Heidegger foi propor um esclarecimento sobre o ser da consciência, que chamará de "ser-aí". É na obra Ser e Tempo que o filósofo apresenta a fenomenologia do ser-aí. O propósito de Heidegger foi desenvolver a noção de ser no mundo com o objetivo de recolocar a questão do "sentido de ser", pois, segundo ele, esta questão foi esquecida pela metafísica tradicional. Ao questionar qual é o "sentido de ser", Heidegger expõe que o ser não é um ente, e que apenas se apresenta por meio da compreensão que o sujeito faz do seu significado. Dessa forma, o ser para Heidegger está ligado ao fundamento da existência, aos vários modos de ser-no-mundo do Dasein.

A segunda parte do artigo mostra que o ser-no-mundo está sempre em correspondência com o mundo. O ser-no-mundo indica um modo de estar lançado em um mundo cheio de possibilidades, assim, o ser-no-mundo está junto aos entes que também se encontram no mundo, além de estar sempre atarefado com algo, mesmo quando pensa que está desocupado. É impossível um ser-no-mundo sem estar no mundo, pois, eles se manifestam em conjunto. No entanto, não é porque o ser-no-mundo se manifesta em conjunto com o mundo que ele não possa tomar um distanciamento das operações cotidianas, Heidegger nomeia este distanciamento de angústia. A angústia é uma tonalidade afetiva, como o medo, a alegria e etc. As tonalidades afetivas determinam o modo que o ser-no-mundo se encontra no mundo.

A angústia faz o ser-aí ter um encontro consigo e o força a compreender as possibilidades de ser, assim, surge o cuidado. O cuidado para Heidegger não é o ato te cuidar de alguém, mas é o que há de mais essencial na existência do Dasein. Para Heidegger, a noção de cuidado esta relacionado com a dimensão temporal, na medida em que o ser humano está sempre com os olhos para o futuro. Ou seja, o cuidado é a estrutura fundamental do homem, dessa forma, o cuidado é o existir no mundo, mas com os olhos sempre direcionados ao futuro. 
A terceira parte expõe que a criança, assim como o adulto, traz consigo uma abertura nova e ao mesmo tempo a capacidade de desvelar das coisas. No entanto, os significados das coisas aparecem para a criança da mesma maneira que para um adulto, porém, isso não quer dizer que os significados das coisas terão o mesmo sentido para ambos, pois, apenas o processo é igual. Assim, busca-se compreender que os vários modos de ser da criança estão diretamente ligados ao contexto histórico e social.

\section{INTRODUÇÃO A HEIDEGGER}

Martin Heidegger (1889-1976) foi um filósofo alemão nascido na cidade de Messekisch no sudoeste da Alemanha. Estudou teologia na Universidade de Freiburg, onde também se formou em filosofia. Tornou-se um dos principais filósofos do seu século ao reformular a fenomenologia de Edmund Husserl. Aos 14 anos, Heidegger foi encaminhado a duas escolas jesuítas. O objetivo era que o filósofo seguisse o caminho religioso. Neste período, ele teve seu primeiro contato com o filósofo e psicólogo alemão Franz Brentano sobre os vários sentidos de ser de Aristóteles. Anos mais tarde, Heidegger abandona a vida religiosa e casa-se com Elfriede Petri, com quem teve dois filhos.

Foi por meio de indicações de revistas filosóficas que Heidegger se interessou pela fenomenologia de Edmund Husserl, que tinha como influência as ideias de Franz Brentano. Anos depois, se dedicou as atividades docentes junto a Husserl, onde voltou a se interessar pela obra Investigações Lógicas, a qual já lhe havia sido apresentada em sua adolescência.

Ao se aproximar de Husserl, Heidegger exercitou seu ver fenomenológico e a partir daí obteve uma nova compreensão de Aristóteles. Foi na obra Investigações Lógicas, mais precisamente na "Sexta investigação" da primeira edição que levou o filósofo a perceber que a distinção entre a intuição sensível e a intuição categorial trazia com ela a múltipla significação do Ente. No entanto, como afirma Kahlmeyer-Mertens (2015, p. 26-27, grifo do autor):

\footnotetext{
O Husserl que Heidegger conhece em 1916 já não era mais o autor das Investigações lógicas (1900). Na data desse contato, Husserl já havia escrito suas Ideias para uma fenomenologia pura e para uma filosofia fenomenológica (1910-1913), isso significava que suas pesquisas já se encontravam em outro nível de desenvolvimento.
} 
Desse modo, Heidegger chega à conclusão de que Husserl não se sentia mais ligado a tal obra.

Husserl almejou encontrar uma verdade fundamental para a consciência humana, ele "[...] reverte o ver fenomenológico à consciência, propondo uma investigação sobre como certas estruturas da consciência estariam envolvidas no conhecimento" (Kahlmeyer-Mertens, 2015, p. 27). No entanto, Heidegger, ao invés de fazer um retorno transcendental como Husserl, propõe um esclarecimento sobre o ser da consciência, que chamará de "ser-aí".

É na obra Ser e Tempo que o filósofo alemão traz a fenomenologia do ser-aí, obra esta que evidência o afastamento entre os dois filósofos. Heidegger desenvolveu a noção de ser no mundo com o objetivo de recolocar a questão do "sentido de ser", pois, segundo ele, esta questão foi esquecida pela metafísica tradicional. Tal esquecimento ocorreu porque a metafísica tradicional se converteu em uma ontologia da substância, isto é, ela tomou a "coisa" como "paradigma de representação para tudo o que é" (BARBOSA, 1998, p. 3).

Ao recolocar a questão do ser, Heidegger afirma que o homem já possui em sua vida diária um pouco do conhecimento do ser, do contrário, tal questão não poderia ser colocada. Assim, para se chegar à compreensão de ser é preciso: "analisar o ser do ente que coloca a questão do ser, isto é, o ser do homem, o dasein" (BARBOSA, 1998, p. 3). Em outras palavras, é necessária uma análise do ser no mundo como base de onde a questão do ser é abordada em geral.

Para se analisar e compreender o ser do dasein, o filosofo utiliza o método fenomenológico. Para o filósofo em questão, a fenomenologia é a análise dos vários modos de aparição, dessa forma, ao se fazer um estudo sobre as estruturas compreensivas, se torna possível que os objetos se mostrem da forma que são. Diz Dan Zahavi:

[...] é preciso compreender o fenômeno como o modo de aparição do próprio objeto. O fenômeno é aquilo que se mostra por ele mesmo - o que se manifesta, o que se revela. De maneira completamente geral, portanto, a fenomenologia pode ser concebida como uma análise filosófica dos diversos modos de aparição e em articulação com isso, como uma investigação reflexiva das estruturas compreensivas, que permitem aos objetos se mostrarem como aquilo que eles são (2019, p. 13). 
Assim, a intenção de Heidegger era compreender o sentido do ser observando as possibilidades de todos os entes, em especial o dasein. O propósito do filosofo foi mostrar o quanto esse ente precisava de uma compreensão do ser e de uma noção original de seu ser.

Ao questionar a diferença entre "o que é o ser" e qual o "sentido de ser", Heidegger deixa evidente que o "sentido de ser" mostra o modo como o ser aparece para o homem. Em vista disso, o filosofo expõe que o ser não é um ente, e que apenas se apresenta por meio da compreensão que o sujeito faz do seu significado. Isto é, o ser para Heidegger esta ligado ao fundamento da existência, nos vários modos de existir, enquanto o ente corresponde à existência humana, como presença no mundo. Para se compreender o sentido de ser é necessário examinar o ente, pois, é neste que se encontra a questão do ser. Dessa forma, Heidegger se concentra na compreensão do ser do ente.

Mas como é possível compreender o significado de ser? Segundo o filósofo alemão, a "compreensão" (Verstehen) é uma característica existencial da experiência humana, portanto, é a partir dela que se abre um espaço significativo no qual algo pode ser entendido como algo.

[...] (concretamente: é desde compreensão que uma pedra de giz pode ser tomada como utensílio de aula, uma caneta como instrumento de escritório). É, assim, na abertura da compreensão, consoante à dinâmica da existência humana, que os sentidos permitem que os entes signifiquem o que sejam, sendo compreendidos enquanto entes. (KAHLMEYER-MERTENS, 2015, p. 45, grifo do autor).

O "sentido" (Sinn) para Heidegger é aquilo que se encontra em um espaço compreensível, onde as significações dos entes se derivam. Isto é, os entes são compreendidos a partir de um determinado sentido que o significam.

Ao questionar o "ser do homem", o filosofo elabora uma analítica do modo de ser do homem. Ou seja, uma analítica que apresente a "essência do homem", que seja capaz de descrever e fundamentar o modo pelo qual o homem é e compreende a si mesmo. É a partir daí que Heidegger realiza a hermenêutica da facticidade do ser-aí. No entanto, o autor não parte do zero, ele faz uma analise das compreensões tradicionais do ser do homem. O filosofo examina as concepções de que o homem é uma soma de alma, corpo e espírito e dotado de razão. As analises feitas por ele exerceram uma virada nas 
concepções tradicionais, pois, é a partir daí que a pergunta sobre "o que é o homem?" passa a ser "quem é o homem?". Ou seja, Heidegger passa a se preocupar com a fundamentação do modo pelo qual é possível questionar "o que é" o homem, "quem" ele é enquanto ser vivo, enquanto um ente existente. Diz ele:

\begin{abstract}
A questão do ser só receberá uma concretização verdadeira quando se fizer a destruição da tradição ontológica. É nela que a questão do ser haverá de provar cabalmente que a questão sobre o sentido de ser é incontornável, demostrando, assim, o sentido em se falar de uma "retomada" dessa questão (HEIDEGGER, 2007, p. 65).
\end{abstract}

Ao elaborar a analítica existencial, o filósofo recoloca a questão ontológica do sentido de ser. Dessa forma, “[...] o caminho de execução da ontologia fundamental carece de uma investigação que elucide esse ente que compreende ser e que, justamente por isso, o pode colocar em questão" (KAHLMEYER-MERTENS, 2015, p. 75). Isto é, a ontologia de Heidegger faz a análise fundamental do ser-aí. Portanto, a analítica existencial trata-se de uma análise fundamental das estruturas existenciais do ser-aí. É a partir de tal análise que se é possível dar continuidade na questão do Ser.

Mas o que é o ser-aí? O ser-aí é algo do humano, é a sua essência, a realidade humana. No entanto, não se pode adotar a palavra homem para se referir ao ser-aí. Pois, “[...] ser-aí não é uma forma diferenciada ou original para se referir a homem, isso porque o ser-aí, tal como tratado na filosofia de Heidegger, não corresponde imediatamente ao que a filosofia chamou de homem" (KAHLMEYER-MERTENS, 2015, p. 77-78, grifo do autor). Isto se esclarece porque a ontologia de Heidegger consiste em compreender o humano, ela trata do ser, algo próximo de uma figura de consciência. O ser-aí se forma existindo, ao existir, o ser-aí se define no ente que é.

A análise fenomenológica mostra o ser-aí como existencial, como afirma Kahlmeyer-Mertens (2015, p. 83), “existenciais são estruturas ontológicas tão somente engendradas na dinâmica da existência; são, portanto, componentes ontológicoexistenciais do ente que somos (= ser-ai)". Portanto, o homem é existente a cada instante, a existência define o ser na situação, por isso, o ser-junto, o ser-em, são algumas partes da existência do ser-aí.

Adiante, tematizaremos a noção do ser-no-mundo, suas propriedades e ocupações. Como o ser-no-mundo se vê em relação à angústia e o cuidado em Ser e Tempo. 


\section{O SER-NO-MUNDO}

Por meio da sua investigação, Heidegger identifica traços fundamentais característicos do ser. O filósofo alemão nomeia esses traços de existenciais. "O ser-nomundo é um existencial" (KAHLMEYER-MERTENS, 2015, p. 85). Deste modo, ser-nomundo é existencial porque mostra como o ser-aí é no espaço que constitui o mundo. Isto é, o ser-no-mundo é sempre em correspondência com o mundo, como afirma KahlmeyerMertens:

\footnotetext{
Ser-no-mundo indica um modo de estar-aí. Um tal modo se expressa na forma de um ser-lançado-em-um-mundo. Nisso se define a situação fática deste ente, circunstância que possui uma familiaridade a esse mundo, e que pode ser compreendida como o conjugar da existência deste ser-aí nessa região ontológica delimitada (2015, p.87).
}

O ser-no-mundo está junto aos entes que também se encontram no mundo (serjunto). Heidegger chama de intramundanos os entes em que o ser-no-mundo possui algum tipo de relação, "[...] entes manuseáveis em certa ocupação" (KAHLMEYERMERTENS, 2015, p. 87). O termo “ocupação" é o comporta-se num espaço, evidenciando o caráter particular do ser-aí. Portanto, é através dos "modos de ocupação" que o ser-no-mundo se realiza enquanto existente.

O filosofo alemão mostra que o ser-no-mundo está sempre atarefado com algo. Até aquilo que se pensa ser uma "desocupação" é considerada uma ocupação. Para ele “os modos de ocupação são, pois, maneiras de o ser-no-mundo existir em relação aos entes no mundo, por meio de seus comportamentos o ser-no-mundo realiza seus projetos existenciais vindo a ser o ente que é na medida de suas possibilidades" (KAHLMEYERMERTENS, 2015, p. 88). Dessa forma, observa-se como a experiência do mundo é constituída a partir da existencialidade do ser-aí.

Heidegger chama de mundanidade a experiência do mundo que é constituinte da existencialidade do ser-aí. A mundanidade como afirma Heidegger no terceiro capítulo de Ser e Tempo, já é em si mesmo um existencial. No entanto, a experiência da mundanidade no mundo não proporciona clareza no modo de existir do ser-aí. Isto ocorre 
porque este se encontra ocupado com os outros entes. Logo, ele encontra-se distraído desse modo existencial de ser. Diz Kahlmeyer-Mertens (2015, p. 89, grifo do autor):

[...] ao ocupar-se cotidianamente, o ente que somos se deixa tomar por uma atitude natural (não predicativa e não teórica) obscurecendo, por completo, os fenômenos eles mesmos. Este comportamento, do mesmo modo que nos absorve na lida prática, está conjuntamente articulado e orientado por um ver circunstancial (Um-sicht) e obscurece a compreensão de nosso caráter constitutivo de existente possível (de ente que pode-ser).

O ser-no-mundo compartilha com os outros um conjunto de sentidos e significados no mundo fático. Isso faz com que o ser-no-mundo interprete, desde o impessoal, um mundo segundo a maneira que os outros pensam. Isto é, "[...] o ser-nomundo, desde o impessoal, interpreta o mundo segundo o que os outros pensam; pensa e age conforme comumente se faz e se expressa costumeiramente desde o empenho de fazer-se com os outros" (KAHLMEYER-MERTENS, 2015, p. 88). Portanto, o ser no mundo se comporta sob a tutela dos outros. Neste caso, "outros" aqui não é algo determinado, como afirma Kahlmeyer-Mertens:

\footnotetext{
Os outros são todos que compartilham um mundo cotidianamente; do mesmo modo, são ninguém, por afinal não possuir identidades nesse constructo que prescreve tacitamente diretrizes de conduta e modos padronizados de se portar nas muitas demandas do mundo cotidiano (2015, p. 92, grifo do autor).
}

Portanto, o ser-no-mundo impróprio é cheio de ocupação junto de outros entes. Assim, o ser-no-mundo acaba se esquecendo de seu privilégio ontológico-existencial achando que é apenas mais um ente que se encontra no mundo.

É impossível um ser-no-mundo sem estar no mundo, pois, eles se manifestam em conjunto. No entanto, não é porque o ser-no-mundo se manifesta em conjunto com o mundo que ele não possa tomar um distanciamento das operações cotidianas, Heidegger nomeia este distanciamento de angústia. A angústia é uma tonalidade afetiva, como o medo, a alegria e etc. As tonalidades afetivas determinam o modo que o ser-no-mundo se encontra no mundo, "dizendo em uma linguagem mais informal: as tonalidades afetivas dão "tom" por meio do qual o ser-no-mundo se dispõe ao mundo, ou ainda, constituem o "caráter de afinação" com o qual o ser-no-mundo aferrado se acha" (KAHLMEYERMERTENS, 2015, p. 98). Heidegger afirma que a angústia é uma tonalidade afetiva 
fundamental, isto quer dizer que, nas palavras de Kahalmeyer-Mentens, “[...] ao afetar o ser-aí, este se põe em contato imediato com seu ser” (2015, p. 99). Isso só é possível porque o ser-no-mundo entoado pela angústia força o ser-aí a ter um encontro consigo, e através daí ele se compreende como um ente que pode ser algo, ou que ao mesmo tempo há a possibilidade de nada ser.

Levando em consideração que a angústia faz o ser-aí ter um encontro consigo e o força a compreender as possibilidades de ser, o cuidado (Sorge), como afirma KahlmeyerMertens (2015, p. 107), "é o que há de mais essencial na existência do ser-no-mundo". Isto é, o cuidado é o ser do ser-aí. Mas em qual proporção o cuidado constrói a essência do ser-aí?

É importante apontar que o cuidado para Heidegger não é o ato de tomar conta de um indivíduo ou cuidar para se curar de alguma enfermidade. O cuidado em Ser e Tempo traz a situação existencial do ser-no-mundo. De um modo ontológico, o cuidado é, nas palavras de Heidegger, uma totalidade originária do ser do Dasein. Isto é, "o cuidado é a estrutura articulada dos vários elementos constitutivos do Dasein" (CARRILHO, 2010, p. 108). Deste modo, o cuidado é considerado pelo filósofo o modo de ser mais originário do ser Dasein.

O cuidado, por ser um modo de ser do Dasein, compreende a si próprio como um ser lançado no mundo, dessa forma, ele é responsável pela execução das várias possibilidades de ser. Isto é, entende-se o Dasein como abertura ao que já está sendo, no entanto, ele está sempre direcionado ao futuro, ao que ainda falta cumprir, assim, parte da condição que se encontra no mundo, como afirma Carrilho (2010, p. 109): “subjaz, aqui, a compreensão de que o ser humano é um ente inacabado, um projeto que se orienta para o futuro, dimensão temporal de abertura às suas possibilidades de ser onde o cuidado é fundamental". Portanto, o Dasein está sempre em direção ao futuro, ao vir a ser, no qual ele é o responsável. O por-vir mostra que o Dasein não é definido no presente e está sempre se lançando para as possibilidades futuras, isto indica que ele é responsável por todas as suas escolhas, logo, sua verdadeira responsabilidade é a de ser si mesmo.

Para Heidegger, a noção de cuidado esta relacionado com a dimensão temporal, na medida em que o ser humano está sempre com os olhos para o futuro. Ou seja, o cuidado é a estrutura fundamental do homem, dessa forma, o cuidado é o existir no mundo, mas com os olhos sempre direcionados ao futuro, “[...] virando-se para aquilo 
que ainda não é, mas que pode ser e para cujo encontro o próprio ser humano está impelido" (CARRILHO, 2010, p. 110).

O relacionar-se, para Heidegger, ocorre por meio de existências desunidas, o que ele chama de co-presença. A co-presença não ocorre através de um individuo isolado, tanto o ser-aqui e o ser-ali se manifestam e mantém-se como ser-no-mundo. Da mesma forma que as coisas do mundo chegam para o ser-aqui o outro também chega. No entanto, o outro não é destituído de presença, pois, ele é e está mediante seu modo de ser-nomundo.

Portanto, pode-se afirmar que a criança, assim como o adulto, também é Dasein. Os significados das coisas aparecem para a criança da mesma maneira que para um adulto, no entanto, isso não quer dizer que os significados das coisas terão o mesmo sentido para ambos, pois, apenas o processo é igual. Melhor dizendo, tanto a criança quanto o adulto se encontram no mundo e se ocupam com as coisas que estão à mão, dessa forma, surge o sentido e o significado das coisas que serão expressas por meio de linguagem, discurso. No entanto, o que separa a criança de um adulto não é uma questão temporal, na qual, o adulto passa seu conhecimento do mundo para a criança, mas trata-se de uma questão espacial, pois, ambos são existência e se encontram no mundo.

Para o filósofo alemão, o espaço tem significado existencial. Mesmo que o euaqui indique a si mesmo, ele demonstra a sua posição espacial do seu modo de ser-nomundo. Isto é, quando se refere ao ser-aqui, ele não está mencionando o ser de si mesmo, mas se referindo ao que está lá. Nas palavras de Heidegger (2007, p. 175, grifo do autor).

\footnotetext{
E até mesmo quando a própria presença diz explicitamente de si mesma euaqui, da determinação pessoal do lugar deve ser compreendida a partir da espacialidade existencial da presença. Na interpretação desta espacialidade, já indicamos que esse eu-aqui não significa um ponto privilegiado da coisa-eu, mas que se compreende como ser-em a partir do lá de um mundo à mão, a que a presença se detém em seus ocupações.
}

Para Heidegger, a distinção entre o ser-com e o ser-no-mundo se dá pelos modos diferentes de se relacionarem com aquilo que vem ao encontro deles. O ser-no-mundo ocupa-se com as coisas intramundanas, enquanto o ser-com está relacionado com a condição existencial da presença, como a cura e o cuidado, o que o filósofo alemão nomeia de preocupação. A preocupação ocorre de duas maneiras: 1) “ela pode, por assim 
dizer, retirar o "cuidado" do outro e tomar-lhe o lugar, nas ocupações, saltando para o seu lugar" (HEIDEGGER, 2007, p. 178, grifo do autor). Neste caso, o outro pode tornarse dependente, dessa forma, o outro deixa de ser capaz de cuidar de si mesmo. Para o filósofo, este tipo de relação faz com que a convivência recíproca termine. No segundo caso, “[...] ainda a possibilidade de uma preocupação que não tanto substitui o outro, mas que salta antecipando-se a ele em sua possibilidade existenciária de ser, não para lhe retirar o "cuidado" e sim para devolvê-lo como tal" (HEIDEGGER, 2007, p. 178-179, grifo do autor). O preocupar-se traz o outro a posição daquele que é responsável e cuida da sua existência. Dessa forma, cada existência ocupa-se do seu cuidar e cuida do outro, na medida em que tenha relação com o seu próprio cuidar-se.

Existem dois modos de se relacionar da co-presença: a primeira é a convivência recíproca. Pode-se dizer que esta é um modo de se relacionar exclusivo, pois, ambos têm ocupações similares e em comum, diz Heidegger: "a convivência recíproca funda-se antes de tudo e muitas vezes de maneira exclusiva, no que, assim, constitui uma ocupação comum" (HEIDEGGER, 2007, p 179). Um bom exemplo é a família, onde todos se ocupam com as coisas da família. A segunda é o empenhar-se que está ligado a determinação e a dedicação. No entanto, o empenhar-se não tem relação com alguma ocupação, ele apenas se preocupa com a própria presença. Em outras palavras, os pais, além de estarem comprometidos com o próprio cuidado, estão comprometidos com o cuidar de seus filhos, mas não em um sentido que tire a responsabilidade de cuidar de si mesmo, mas de um modo que se antecipa e devolva o cuidar para seus filhos. Portanto, percebe-se que a criança, assim como um adulto, é um ser-no-mundo, ou seja, como mencionado anteriormente, ela também é dasein. A seguir, elucidaremos os vários modos de ser na infância.

\section{OS MODOS DE SER NA INFÂNCIA}

Entendido que a criança por ser-no-mundo também é um dasein, fica o questionamento, como é o modo de ser de uma criança nas atividades diárias. Para esclarecer esta questão, partimos de um princípio de que a compreensão da infância foi, por muito tempo, deixada de lado. 
Até por volta do século XII, na Europa, entre o fim da idade média e o começo da modernidade, não se mencionava a infância, e nem buscavam representá-la. Houve um momento, no século XVI, que a criança era considerada um ser frágil, pois era alto o índice de mortalidade infantil naquela época. Era muito comum os pais terem seus filhos já pensando que alguns não iriam sobreviver. Assim, era normal compreender essa fase da vida como algo inicial, sem muita importância.

Foi no decorrer do século XVII que começou a surgir a separação entre criança e adulto, porém, nesse período, a infância ainda era tratada como dependência e submissão. No século XVIII, com o iluminismo, a responsabilidade de ensinar a razão e o caráter para as crianças eram dos adultos. No entanto, eles as tratavam como folhas em branco que precisavam ser preenchidas, dessa forma, as particularidades das crianças eram deixadas de lado.

Com a proposta iluminista de transformar os homens através da razão, a formação educacional da criança passou a ter espaço. Porém, esta preocupação, "tomava como plano a infância como uma fase transitória que precisa ser apressada" (BARRETO, 2014, p.16). Desse modo, a criança era vista como um adulto em miniatura.

Observa-se que em cada época a infância e as expectativas em cima da criança são concebidas de uma forma diferente. Tais expectativas interferem e delineiam na construção dos vários modos de ser da criança. Por consequência, irão “[...] conduzir modos de ser de crianças, adolescentes e adultos, correspondendo também a interesses culturais, políticos e econômicos de acordo com o contexto da época" (BARRETO, 2014, p. 20). Com isso, o conhecimento que se tem hoje sobre os modos de ser da infância estão intimamente ligados ao meio social em que ela vive e na relação que tem com o outro.

Segundo Barreto, o filósofo francês Gaston Bachelard (1884-1962), apresenta aspectos que estão ligados aos vários modos de ser na infância. De acordo com Bachelard, ao decorrer da infância se vive as solidões primeiras. Essas solidões são momentos de calma, sonhos e paz de uma criança. Ao decorrer da vida, estes momentos se tornam para os adultos devaneios, momentos onde se voltam para si. Neste processo, a infância surge por meio de memorias, assim, o adulto se depara com o próprio ser das solidões primeiras.

O autor aponta a distinção entre a solidão da criança e do adulto. Para a criança a solidão é mais fechada, menos social, e provavelmente, só será revisada e compreendida na fase adulta. "Assim, ao que parecem, os devaneios solitários voltados para os 
devaneios da infância levam ao reencontro até ao conhecimento de modo de ser já esquecido" (BARRETO, 2014, p. 41). Em outras palavras, relembrar os momentos da infância pode levar ao vir a ser, já que esta experiência pode ser lembrada e vivida novamente. A infância é a abertura para um mundo onde há várias possibilidades de ser. Para Heidegger, os vários modos de ser classificam como cuidado.

A criança traz consigo uma abertura nova e ao mesmo tempo a capacidade de desvelar das coisas. A abertura, como mencionado no capítulo interior, é uma característica do Dasein, portanto, não é algo apenas da criança. A abertura é "[...] uma condição constitutiva do ser, que se dá sempre na relação com o outro e com o mundo" (BARRETO, 2014, p. 42). Assim, a abertura é o modo como às coisas vêm ao encontro.

Ao entrar em contato com o mundo, a criança possui vários modos, um deles é o brincar. Segundo Barreto, Heidegger comenta sobre várias especificidades das crianças, umas delas é o jogo. O termo alemão que o filósofo utiliza para se referir ao jogo (spiel) traz um significado muito mais vasto do que na língua portuguesa, pois, também envolve brincadeiras e atividades lúdicas, diz Barreto, “[...] como a interpretação de um papel em uma peça teatral, ou a manipulação de um instrumento musical” (2014, p. 42). Dessa forma, o termo jogo está ligado ao modo de expressão de linguagem.

Não se deve classificar os jogos como algo de criança ou de adulto. "A brincadeira compreendida como algo da criança que nos diz que o jogo de algum modo é pertinente ao ser" (BARRETO, 2014, p. 44). A alegria que se sente ao jogar é uma tonalidade afetiva. Por isso, o jogar é uma forma de encontrar-se sempre disposto. Portanto, como afirma Barreto (2014), pode-se pensar que a criança joga porque é um ser-aí, e não porque é uma criança.

\footnotetext{
As regras do jogo não são normas fixas, estas só se formam em meio ao jogar. Não se joga porque há um jogo, mas sim o oposto, há jogo porque jogamos. $\mathrm{O}$ jogar se desenrola em meio a um jogo, este cria para si mesmo o espaço interior do qual pode se formar transformando-se ao mesmo tempo (BARRETO, 2014, p. 44).
}

Isto é, Heidegger compreende o termo jogo como algo amplo e originário. Dessa maneira, enfatiza que o ser-aí está sempre em jogo durante sua existência.

Portanto, é preciso partir do princípio ontológico fundamental do ser-aí para se compreender o ser-aí das crianças. Isto é, “[...] como já apontado anteriormente, 
compreendê-las como ser-aí, no-mundo, com-os-outros, no espaço, no tempo, sendo abertura, disposição e compreendendo" (BARRETO, 2014, p. 45). Pois, o que está em jogo quando se trata do ser criança é o ser-aí humano, o caráter histórico, mesmo a criança ainda não o conheça. Assim sendo, o fato da criança não ter compreensão do seu caráter de ser-no-mundo não quer dizer que ela é inacabada, pelo contrário, isto faz com que a criança perceba o mundo de uma maneira a descobrir novas possibilidades.

\section{CONCLUSÃO}

Este trabalho iniciou-se com uma introdução a vida do filósofo em questão. Buscou-se explicar sua trajetória na filosofia, e suas principais influências, além de trazer seus principais conceitos. Isto foi necessário para que o leitor pudesse entender como Heidegger compreendeu o ser-no-mundo, principalmente o ser-no-mundo na infância.

Heidegger buscou reformular a metafísica tradicional trazendo novamente à tona a questão do ser. No entanto, o filósofo questiona o "sentido de ser" e não o "que é o ser”, como na metafísica clássica. Dessa forma, surgiu à fenomenologia do ser-aí. É a partir de tal análise que se é possível dar continuidade na questão do Ser. Ao questionar o "ser do homem", o filosofo elabora uma analítica do modo de ser do homem. Ou seja, uma analítica que apresente a "essência do homem", que seja capaz de descrever e fundamentar o modo pelo qual o homem é e compreende a si mesmo.

Através da sua investigação, Heidegger identifica traços fundamentais característicos do ser, tais traços são considerados pelo filósofo existenciais. Segundo ele, o ser-no-mundo é um existencial, pois, mostra como o ser-aí é no espaço que constitui o mundo. Isto é, o ser-no-mundo é sempre em correspondência com o mundo.

Portando, as crianças, assim como os adultos, são "ser-no-mundo", elas se encontram no mundo. Os significados das coisas aparecem para a criança da mesma maneira que para um adulto, no entanto, isso não quer dizer que os significados das coisas terão o mesmo sentido para ambos, pois, apenas o processo é igual. Melhor dizendo, tanto a criança quanto o adulto se encontram no mundo e se ocupam com as coisas que estão à mão, contudo, os vários modos de ser criança e de compreender as coisas são diferentes dos vários modos de ser e de compreender de um adulto. 
Os vários modos de ser criança revelam o cuidado, que está sempre direcionado ao futuro. Mesmo não possuindo compreensão sobre o por-vir, a criança, assim como o adulto esta direcionada ao futuro. Por isso, o por-vir mostra que o Dasein não é definido no presente e está sempre se lançando para as possibilidades futuras, isto indica que ele é responsável por todas as suas escolhas. Portanto, sua verdadeira responsabilidade é a de ser si mesmo.

Consequentemente, conclui-se que, o que está em jogo para Heidegger é o ser-aí humano, independentemente de ser criança ou adulto. Quando se trata do ser criança, o fato dela não ter compreensão do seu caráter de ser-no-mundo não quer dizer que ela é inacabada, pelo contrário, isto faz com que a criança perceba o mundo de uma maneira a descobrir novas possibilidades.

\section{REFERÊNCIAS BIBLIOGRÁFICAS}

HEIDEGGER, Martin. Ser e Tempo. Trad. Marcia Sá Cavalcante Schuback. 2 ed. Petrópolis: Vozes; Bragança Paulista: Editora Universitária São Francisco, 2007.

KAHLMEYER-MERTENS, Roberto S. 10 lições sobre HEIDEGGER. Petrópolis: Vozes, 2015.

ZAHAVI, Dan. Fenomenologia para iniciantes. Trad. Marco Antonio Casanova. 1 ed. Rio de Janeiro: Via Verita, 2019.

BARBOSA, Marcio F. A Noção de Ser no Mundo em Heidegger e sua Aplicação na Psicopatologia. Psicologia Ciência e Profisssão. Brasília. n.3, v.18, p. 2-13, 1998.

CARRILJO, Marília Rosado. O cuidado como ser e o cuidado como agir. Ex aequo, Vila Franca de Xira, n.21, p. 107-114, janeiro, 2010.

BARRETO, Aline Leite. Uma compreensão fenomenológico-existencial dos modos de ser criança. Mestrado em educação: Psicologia da Educação. Pontifícia Universidade católica de São Paulo - PUC. São Paulo, p. 93. 2014.

MACHADO, Marina Marcondes. Childhood \& Philosophy. Infância e Corpo Encarnado / uma perspectiva Poético-existencial para o Ser Criança. Rio de Janeiro, v. 12, n.24, maiago, p. 455-468, 2016. 